Anuario de Estudios Medievales (AEM)

37/1, enero-junio de 2007

pp. 411-416

ISSN 0066-5061

\title{
EL RETAULE \\ DE SANTA MAGDALENA DE LES TRAGINES. EPÍLEG
}

SANTA MAGDALENA DE LES TRAGINES ALTARPIECE. EPILOGUE

M. CARMEN RIU DE MARTÍN Secretària de "Índice Histórico Español"

Resum: Revisió del treball que amb el mateix títol es va publicar a la revista "Anuario de Estudios Medievales", 36/1 (2006), pp. 355-384. La restauració de les peces estudiades ha permès obtenir nous resultats sobre la iconografia $\mathrm{i}$ el sentit simbòlic de les imatges plasmades a l'esmentat retaule.

Paraules clau: Retaule; Iconografia; Temàtica de martiri.

\begin{abstract}
This is a work review of the article published in "Anuario de Estudios Medievales” 36/1 (2006), pp. 355-284. After the restoration of the pieces one has obtained new data about their iconography and their image's symbolism.
\end{abstract}

Keywords: Altarpiece; Iconography; Martyrdom subject.

Després de la restauració de les dues taules a l'Escola Superior de Conservació i Restauració de Béns Mobles de la Generalitat de Catalunya al barri de la Trinitat de Barcelona, s'ha pogut arribar a deduir el següent:

Aquestes dues taules foren reaprofitades en una etapa posterior a la seva creació al principi del segle XVI i transformades en dos sants diferents: Santa Magdalena i Sant Lleïr tot i que procedien de la mateixa mà. El sant portava una barba afegida que s'ha eliminat, quedant transformat en una dona.

Aquesta modificació ens permet considerar que ambdues pintures pertanyien inicialment al mateix retaule i la mateixa santa. Tot i que durant anys serviren com a símbol de Santa Magdalena la una i Sant Lleïr l'altra, al formar part d'esglésies rurals privades o capelles de masies annexades al municipi de Pedra i La Coma (actualment La Coma i La Pedra) i que no tenien cap relació directa amb la parroquia de Sant Llorenç de Morunys, ni amb la Confraria dels Colls. Encara que ara s'exhibeixen al Museu Patronat Vall de Lord, de Sant Llorenç de Morunys.

Degut a que les representacions iconogràfiques dels sants es basen en les accions destacades que aquests varen portar a terme durant la seva vida. Les dues taules de la santa no tenen perquè correspondre obligatoriament a 
santa Magdalena, ja que en cap moment va morir martiritzada. De totes maneres a partir del segle XIV la llegenda de conversió i matiri van plegades.

De fet no sabem com varen arribar a la comarca de la Vall de Lord aquestes taules, si foren una creació local, o bé va ser pel comerç, ja que ambdues possibilitats es poden admetre. A més el bust de Santa Caterina es troba representat al retaule del segle XV de Sant Joan Baptista i Sant Miquel Arcángel que es creuen procedents de Solsona. L'informe efectuat després de la seva restauració considera que la santa era Caterina d'Alexandria, també màrtir. Hi havia hagut una pintura gótica del segle XIII dedicada a la Santa a l'intradós de l'arc del primer pilar que separa la nau central de la lateral dreta de l'església romànica de Sant Llorenç de Morunys. Ara aquesta pintura al fresc està repicada i no s'ha pogut recuperar. La confraria laica dels Colls era la que des del segle XIV financià moltes activitats litúrgiques, altars, imatges, etc...i Santa Caterina no fou mai una figura central; es més, fins a la darreria del segle XVIII no es va fer un altaret adossat al pilar esmentat presidit per una imatge escultòrica de la santa, el qual va ser cremat l'any 1936. No tenim notícia, ni documentació de cap creació pictórica relacionada directament amb Santa Caterina, tret de la representació petita del retaule de Sant Joan i Sant Miquel, de mig del segle XV, si bé no podem descartar l'existència d'un culte a Santa Caterina a l'església parroquial (aquesta fou la patrona de les noies casaderes), previ a la constitució de la confraria del mateix nom a Sant Llorenç, documentada a partir de 1711 a l'Arxiu Parroquial.

Els dubtes que es presenten per fer una atribució rigorosa són que les imatges del retaule en primer lloc mostren la santa despullada de mig cos i santa Caterina acostuma a ser representada vestida, tot i que la plasmen al costat d'un àngel — com en aquesta pintura - portant la seva ànima al cel. Pel que fa a les dues rodes del matiri que ajuden a reconeixe-la, en aquest cas consisteixen en una sella femenina de muntar lateralment girada per seure de costat al cavall.

La llegenda de Santa Caterina gira al voltant de l'Emperador Magènci o Maximí que prohibí el culte cristià a Alexandria i decretà el matiri d'aquells que desobeissin l'ordre. Empresonada per l'emperador fou visitada per aquest i Porfiri - un oficial de la cort que també es convertí-, i fou ajudat per un altre dignatari de la cort. Després de ser martiritzada pels seus soldats amb la roda, la decapitaren. Els àngels transportaren el seu cos a la muntanya del Sinaí. Si fos certa aquesta hipótesi en la primera taula es veuria com la santa agenollada és assotada per dos soldats davant l'emperador - que porta una corona d'or-, l'emperatriu i la cort, i a la segona com és visitada per aquests dignataris i està a punt de ser martiritzada sota la protecció d'un àngel. Tot $\mathrm{i}$ que alguns aspectes iconogràfics no coincideixen totalment, ja que no va ser assotada amb fuets fets de cues de cavall com a altres imatges i la resta de diferencies ja les hem esmentat. No es pot descartar tampoc aquesta possibilitat. 
Una tradició local deia que al retaule de les Tragines hi havia representada la figura de Jesucrist predicant des d'una trona, representació molt més inversemblant i fruit d'una falsa interpretació popular.

Data de recepció de l'article: octubre 2006.

Data d'acceptació i versió final: març 2007. 


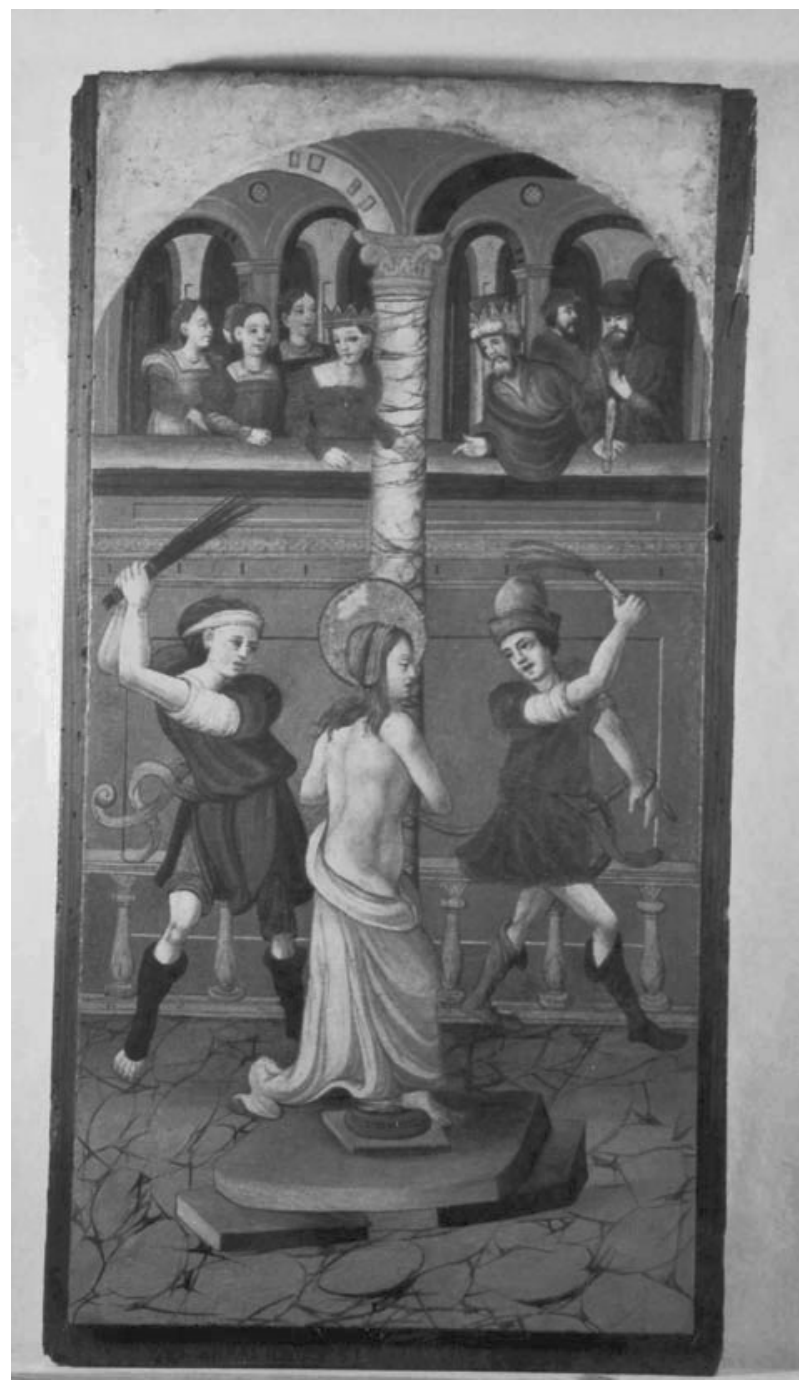

Fig. 1. Taula amb l'escena del martiri després de ser restaurada. 


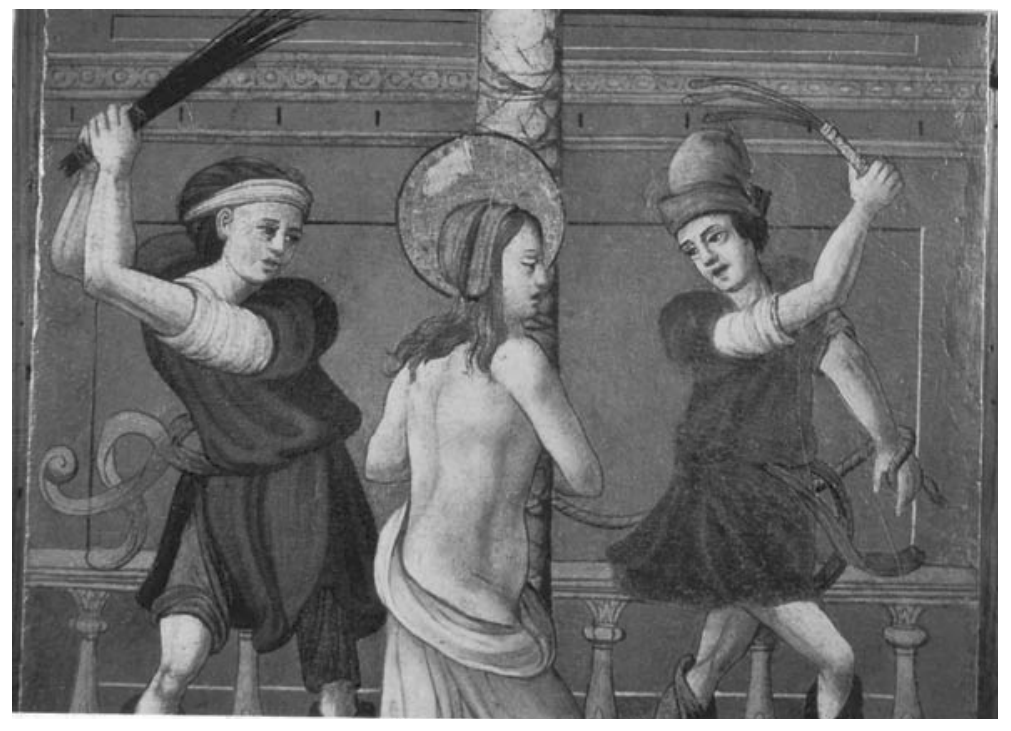

Fig. 2. Detall de l'escena del martiri amb la figura sense barba després de ser restaurada. 


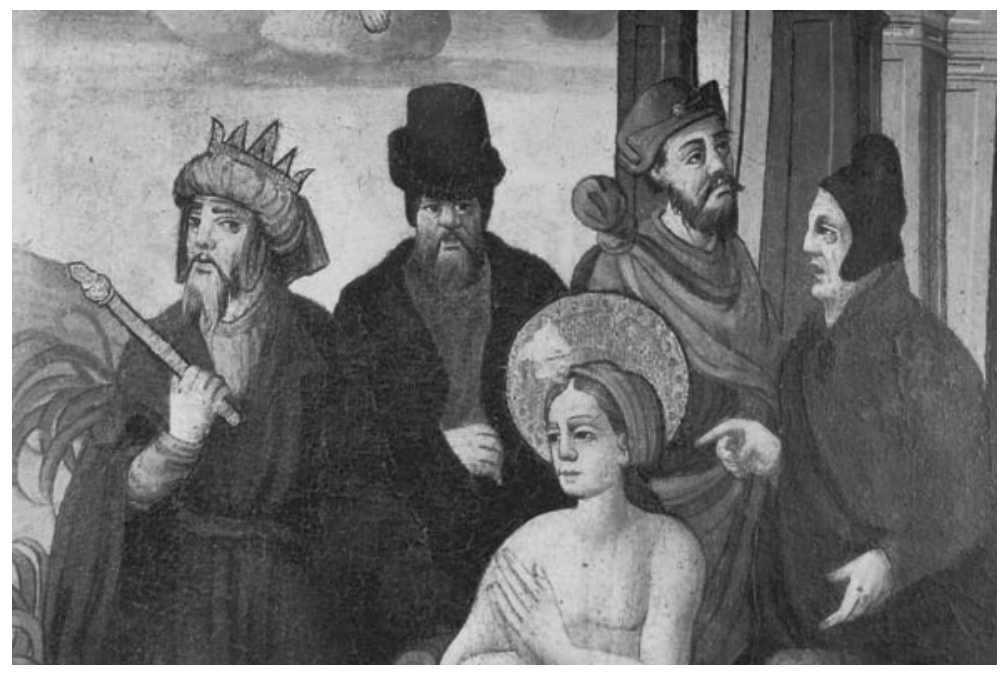

Fig. 3. Segona taula amb la figura de la santa i uns personatges de la cort després de ser restaurada. 